\title{
Effect of smoking on urothelial cancer risk in individuals with Lynch syndrome
}

\author{
Wendy Kohlmann ${ }^{1 *}$, Lisa M Pappas ${ }^{1}$, Kory Jasperson ${ }^{1}$, Deborah W Neklason ${ }^{1}$, Randall W Burt ${ }^{1}$, Jeffrey N Weitzel ${ }^{2}$, \\ Elena M Stoffel ${ }^{3}$ \\ From 13th Annual Meeting of the Collaborative Group of the Americas on Inherited Colorectal Cancer \\ Honolulu, Hawaii, USA. 16-17 October 2009
}

\section{Background}

Cigarette smoking is a well-described risk factor for a number of cancers and has been implicated as the most significant cause of urothelial cancer, conferring up to a 7 -fold increased risk. Urothelial cancers are also part of the spectrum of cancers associated with Lynch syndrome. Several studies have looked at the impact of gene-environment interaction on cancer risk in Lynch syndrome and have found that smoking may increase the risk for colorectal cancer. However, the interaction of smoking and mismatch repair (MMR) genotype has never been evaluated for urothelial cancer risk.

\section{Methods}

Three existing cancer registry data sets are being utilized for this analysis including Colon-Cancer Family Registries, Dana-Farber Cancer Institute, and City of Hope. These data sets contain information about individuals with confirmed MMR gene mutations, age, race, gender, cancer diagnoses, and smoking status. Subjects were recruited using different strategies, with some being identified through population based recruitment and others being identified through high-risk clinics. Urothelial cancers included transitional cell cancers of the collecting system and bladder. Individual subject data will be assigned weights associated with inverse probability of being included in the sample based on recruiting methods and stratified to account for population versus clinic recruitment. A standardized incidence ratio (SIR) will be calculated by comparing the observed versus expected number of urothelial cancers among smokers and nonsmokers with MMR repair mutations. SEER data will be used to determine the expected

* Correspondence: wendy.kohlmann@hci.utah.edu

${ }^{1}$ University of Utah Huntsman Cancer Institute, 2000 Circle of Hope, Salt Lake City, Utah 84112, USA number of cancers. Poison regression techniques will be used to determine if smoking has a significant effect on the SIRs.

\section{Results}

From these three datasets, 1185 MMR mutation carriers were identified, and smoking data was available for 1107 (93.4\%). Subjects were dichotomized as ever smokers if they had ever smoked a cigarette a day for three or more months or never smokers. Based on this definition 580 (52.4\%) were never smokers, and 527 (47.6\%) were smokers. There were a total of 34 urothelial cancers diagnosed in the entire study population, corresponding to a prevalence of $3.1 \%$. The mean age at diagnosis of urothelial cancer was 55.5 years (range 34-79 years). Urothelial cancer was the first cancer diagnosis in 10 cases $(29.4 \%)$. Thirteen $(38.2 \%)$ had one prior cancer, and $11(32.4 \%)$ had two or more prior cancers. Smoking data were available on 26 cases. Of those, 16 (61.5\%) occurred in nonsmokers, and 10 (38.5\%) occurred in smokers.

\section{Conclusion}

Our data suggest that the prevalence of urothelial cancer in MMR mutation carriers is approximately $3 \%$. Risk estimates will be adjusted for age and gender and appropriately weighted and stratified to account for subject ascertainment, in order to complete our calculation of the SIR. Determining the role of gene-environment interactions will be important for understanding differences in cancer risk among Lynch syndrome families and for targeting modifiable lifestyle factors for risk reduction.

\section{Acknowledgement}

We acknowledge the use of the Genetic Counseling and Biostatistics, and Survey Research Shared Resource which are supported by the Huntsman 
Cancer Foundation and an NCl Cancer Center Support Grant 5 P30 CA042014. The City of Hope hereditary cancer registry is supported in part by a General Clinical Research Center grant from NIH (MOI RR00043) awarded to the City of Hope National Medical Center, Duarte, California.

\section{Author details}

${ }^{1}$ University of Utah Huntsman Cancer Institute, 2000 Circle of Hope, Salt Lake City, Utah 84112, USA. ${ }^{2}$ City of Hope, Duarte, California 91010, USA. ${ }^{3}$ Brigham and Women's Hospital/Dana-Farber Cancer Institute, Boston, Massachusetts

02115, USA.

Published: 25 May 2010

doi:10.1186/1897-4287-8-S1-O6

Cite this article as: Kohlmann et al:: Effect of smoking on urothelial cancer risk in individuals with Lynch syndrome. Hereditary Cancer in Clinical Practice 2010 8(Suppl 1):06.

\section{Submit your next manuscript to BioMed Central} and take full advantage of:

- Convenient online submission

- Thorough peer review

- No space constraints or color figure charges

- Immediate publication on acceptance

- Inclusion in PubMed, CAS, Scopus and Google Scholar

- Research which is freely available for redistribution

Submit your manuscript at www.biomedcentral.com/submit 